\title{
Acmella marajoensis G.A.R. Silva \& J.U.M. Santos: Uma nova espécie de Asteraceae para a Amazônia brasileira'
}

Genilson Alves dos Reis e SILVA', João Ubiratan Moreira dos SANTOS²

RESUMO

Em decorrência dos estudos na subtribo Ecliptinae da Amazônia brasileira, é descrita uma nova espécie, Acmella marajoensis G.A.R. Silva \& J.U.M. Santos. Até o presente momento, a espécie é considerada como endêmica da Ilha do Marajó. São apresentados diagnose em latim, descrição detalhada, comentários taxonômicos e ilustraçôes.

PaLAVRAS-CHAVE: Compositae, Ecliptinae, Acmella, Ilha do Marajó

\section{Acmella marajoensis G.A.R. Silva \& J.U.M. Santos: a new species of Asteraceae for the Brazilian Amazonia}

\section{ABSTRACT}

As result of subtribe Ecliptinae studies from Brazilian Amazonia, is described here a new species, Acmella marajoensis G.A.R. Silva \& J.U.M. Santos. At the present moment, this species had been considered as endemic of the Marajó Island. Latin diagnosis, detailed description, taxonomic commentaries and illustrations are presented.

KEYWORDS: Compositae, Ecliptinae, Acmella, Marajó Island

1 Instituto Federal de Educação Ciência e Tecnologia do Piauí - IFPI - Campus Uruçuí, Rodovia 247 Km 07 s/n. Piauí, Brasil. e-mail: genilson.alves@ifpi.edu.br.

${ }^{2}$ Universidade Federal Rural da Amazônia - UFRA - Avenida Perimetral s/n, bairro Terra Firme, Belém, Pará, Brasil. e-mail: bira@museu-goeldi.br 


\section{INTRODUÇÃO}

Acmella Rich. in Pers. foi estabelecido em 1807 e é constituído de 30 espécies herbáceas, anuais ou perenes (Jansen 1985). O gênero é pantropical, com espécies ocorrentes em diversos continentes, como na América do Norte, América Central e do Sul; África (Madagascar); na Ásia; e Oceania. Moore (1906) considerou este gênero como uma seçáo de Spilanthes Jacq. que compreendia 26 espécies.

Jansen (1981) realizou um tratamento taxonômico para as espécies de Spilanthes mencionando apenas seis espécies de distribuiçáo restrita a solos arenosos da América do Sul, Índia, norte da Austrália, Malásia e nas porções central e oeste da África.

Ao realizar a revisão de Acmella, Jansen (1985) considerou o gênero como independente, efetuando novas combinaçôes da maioria das espécies de Spilanthes a Acmella. Dessa forma, Spilanthes passou a ser composto por seis espécies, ao passo que Acmella, antes discutido como uma seção de Spilanthes é atualmente reconhecido como independente e circunscreve 30 espécies.

As espécies de Acmella são geralmente caracterizadas como ervas, eretas ou decumbentes; filotaxia rosulada ou distribuída ao longo dos ramos, lâminas filiformes ou largamente ovaladas; capítulos ovalados, radiados ou discóides; receptáculo cônico; páleas douradas, ou rosadas a avermelhadas, ápice obtuso a acuminado; flores do raio, quando presentes, liguladas, pistiladas, corola branca, amarela a amarelo-alaranjada, com dois ou três lacínios no ápice; flores do disco perfeitas, tubulosas, corola branca, amarela ou amarelo-alaranjada, quatro ou cinco lacínios agudos, anteras quatro a cinco, amarelas; cipselas do disco lateralmente comprimidas, ovaladas ou elipsóides, às vezes com margem cortical presente na maturidade, pápus ausente ou com 1 a 10 cerdas frágeis; cipselas do raio, tricostadas, elipsóides, geralmente com margem cortical presente na maturidade, papus ausente ou com 1 a 10 cerdas frágeis (Jansen 1985).

Na obra Flora Brasiliensis, Baker (1884) mencionou seis táxons, do gênero Spilanthes, atualmente enquadrados no gênero Acmella.

Jansen (1985) citou dez espécies de Acmella para o Brasil, ocorrentes em diversas partes do território nacional, a saber: Acmella bellidioides (Smith in Rees) R.K. Jansen, $A$. brachyglossa Cass., A. ciliata (Kunth) Cass., A. decumbens var. decumbens R.K. Jansen, $A$. leptophylla (DC.) R.K. Jansen, $A$. oleracea (L.) R.K. Janen, A. psilocarpa R.K. Jansen, A. pusilla (Hooker e Arnott) R.K. Jansen, A. serratifolia R.K. Jansen e A. uliginosa (Sw.) Cass. Dessas, Acmella serratifolia R.K. Jansen e Acmella psilocarpa R.K. Jansen são descritas como novas espécies para a ciência.
Mondin et al. (2010) registraram pela primeira vez a ocorrência das seguintes espécies: Acmella alba (L'Hér.) R.K. Jansen; A. oppositifolia R.K. Jansen e A. paniculata (Wall. ex DC.) R.K. Jansen, contribuindo para um maior conhecimento da distribuição geográfica brasileira do gênero Acmella.

$\mathrm{Na}$ Amazônia brasileira, até a realização deste trabalho, cinco espécies do gênero Acmella haviam sido citadas, $A$. brachyglossa Cass., A. ciliata (Kunth) Cass., A. oleracea (L.) R.K. Jansen, A. oppositifolia R.K. Jansen e A. uliginosa (Sw.) Cass. (Silva 2008; Mondin et al. 2010).

\section{MATERIAL E MÉTODOS}

O presente trabalho foi desenvolvido durante o estudo da subtribo Ecliptinae na Amazônia brasileira, através de consultas ao acervo dos herbários HAMAB, IAN, INPA, MG, RB e R, acrônimos segundo Holmgren et al. (1990).

A descrição foi baseada exclusivamente em material herborizado; foram observadas ao estereomicroscópio as características morfológicas dos ramos e folhas, indumento e tipologia de tricomas e padrão de nervaçáo, cuja nomenclatura foi descrita conforme Hickey (1973), Radford (1974) e Rizzini (1977). A mensuração das estruturas vegetativas foi efetuada através da utilização de um paquímetro. Para as estruturas reprodutivas, foi feita a hidratação dos capítulos e as medidas obtidas sobre papel milimetrado, sempre considerando as extremidades.

As ilustraçóes dos caracteres vegetativos foram confeccionadas com base nos espécimes contidos no holótipo. As estruturas reprodutivas foram ilustradas em câmara clara acoplada a um estereomicroscópio.

\section{RESULTADOS E DISCUSSÃO}

Uma nova espécie para o gênero Acmella foi detectada. As exsicatas coletadas no município de Soure, na Ilha do Marajó, Pará, continham diversos indivíduos que haviam sido identificados como Spilanthes sp. e Eclipta sp., permanecendo assim, incorporados junto a esses gêneros. Após análise minuciosa do material, com base na fotografia dos tipos, descrições obtidas da revisão do gênero contidas em Jansen (1985), bem como, consultas aos acervos do Jardim Botânico do Rio de Janeiro (RB) e Museu Nacional (R) foi constatado que se tratava de uma nova espécie para a ciência.

Acmella marajoensis G.A.R. Silva \& J.U.M. Santos, sp. nov. - Tipo: BRASIL. Pará: Soure, Ilha do Marajó, Rio São Lourenço, campo de pastagem da Fazenda Santo André, próximo a Fazenda Riclândia, 21/IX/1969, fl., fr., E. Oliveira 4971 (Holótipo: IAN). Figura 1.

Herba, erecta, pauci ramosa; folia opposita, ovato-lanceolata, glabra ad sparse strigosa in facie adaxiali, apice acuto, base leviter cuneata, margine inconspicue serrata, sparse ciliata; capitula 

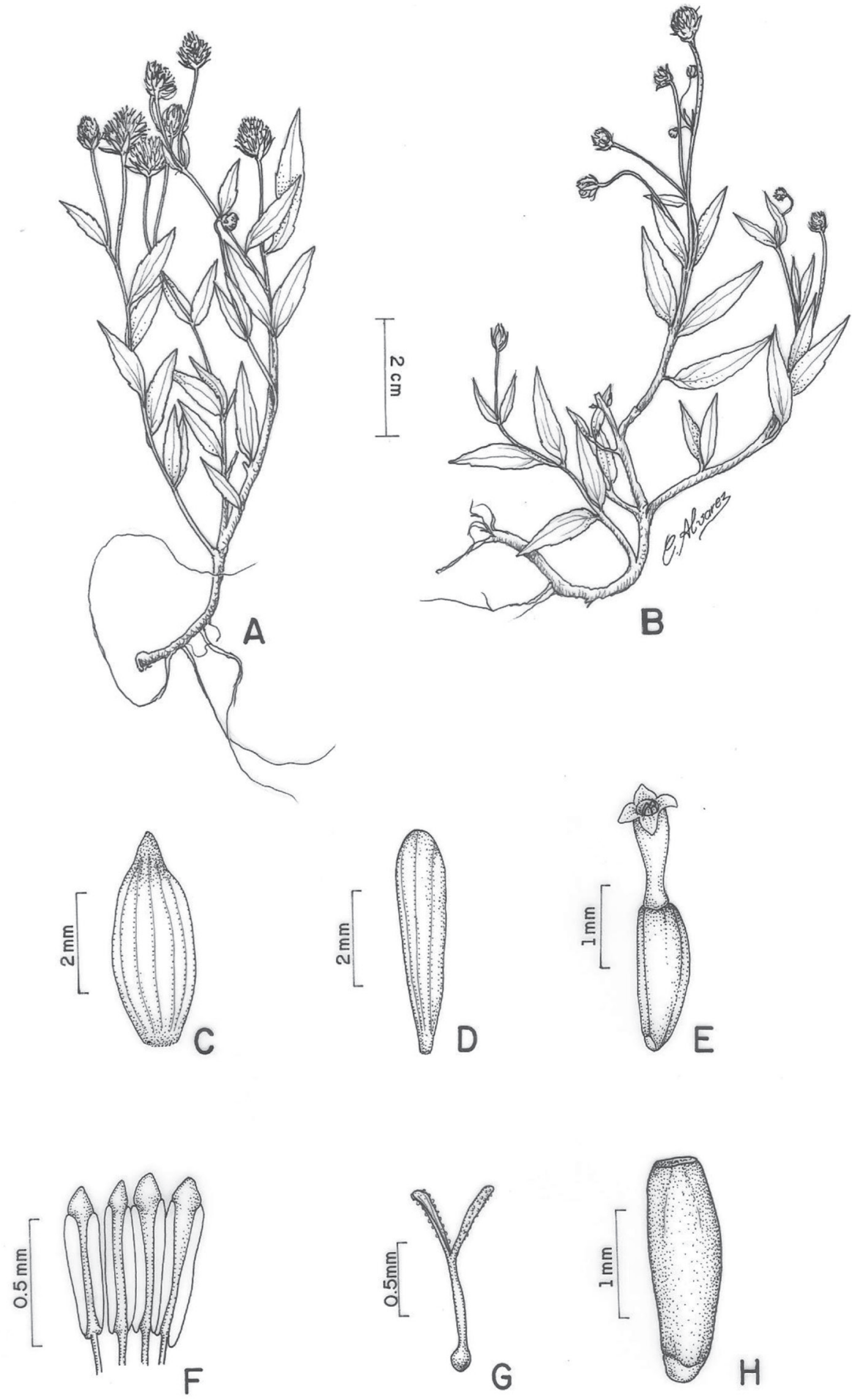

Figura 1 - Acmella marajoensis G.A.R. Silva \& J.U. Santos. A e B - Hábitos; C - Bráctea involucral; D - Pálea; E - Flor; F - Anteras; G - Estilete e ramos estigmáticos $\mathrm{H}$ - Cipsela. 
discoidea, involucrum uniseriatum; paleae ca. 4,0 $\mathrm{mm} \times 1,0 \mathrm{~mm}$, oblongo-lanceolatae, leviter curvatae, glabrae; flores 70-80 per capitulum, androgyni, corolla ca. $1,5 \mathrm{~mm}$ longa, fulva, lacyniae 4; antherae 0,6-0,7 mm longae, castaneo-pallidae; stylum 0,6-0,8 mm longum, cypselae 1,7-2,0 mm longae et 0,5-0,7 mm diam., oblanceolatae, compressae, glabrae, nigrae; carpopodium laterale, conspicuum; pappus nullus.

Erva 10 a $30 \mathrm{~cm}$ altura, anual, ereta, pouco ramificada, base dos ramos sublenhosa. Ramos cilíndricos, sulcados, glabros na base e esparsamente estrigosos no ápice; entrenós 0,8-3,0 cm comprimento, conspícuos.

Folhas decussadas, sésseis ou com pecíolo ca. $3,0 \mathrm{~mm}$ comprimento; lâmina estreitamente oval-lanceolada, 1,4 $3,0 \mathrm{~cm}$ comprimento $\times 0,5-0,9 \mathrm{~cm}$ largura, verde concolor, membranácea; ápice agudo, base levemente cuneada, margem inconspicuamente serreada e esparsamente ciliada; face adaxial glabra, face abaxial glabra a esparsamente estrigosa nas nervuras; nervação campidódroma-eucampidódroma.

Capítulos dispostos em capitulescências terminais, discóides, 0,6-0,9 cm comprimento x 0,5-0,6 diâmetro; pedúnculo $1,5-3,5 \mathrm{~cm}$ comprimento, glabro; invólucro unisseriado, brácteas involucrais de seis a oito, verde-claras, ovalado-lanceoladas, 4,0 mm comprimento x 1,5-2,0 mm largura, ápice agudo, margem inteira, glabras em ambas as faces, membranáceas; receptáculo cônico, 4,0 - 5,0 mm comprimento x 1,0 mm diâmetro; páleas amarelo-douradas, espatuladas, ca. 4,0 mm comprimento x $1,0 \mathrm{~mm}$ largura, levemente curvas, glabras, pouco estriadas, ápice arredondado.

Flores 70 a 80, amarelas, perfeitas, tubulosas; corola ca. 1,5 mm comprimento, lacínios 4, deltóides, glabros na face externa, papilosos na face interna, base do tubo dilatada; anteras 0,6-0,7 mm comprimento, filetes ca. $0,5 \mathrm{~mm}$ comprimento, apêndice do conectivo oval, tecas castanho-claras, base curtosagitada a atenuada; ovário oblongo a oblongo-lanceolado, 1,7 - 1,9 mm compr. x 0,5-0,7 mm diâmetro, glabro, pardo; estilete $0,6-0,8 \mathrm{~mm}$ comprimento, estilopódio presente, ramos estigmáticos $0,5-0,7 \mathrm{~mm}$ comprimento, ápice obtuso, papiloso na face externa; carpopódio lateral conspícuo. Cipselas obpiramidais, $1,7-2,0 \mathrm{~mm}$ comprimento $\mathrm{x} 0,5-0,7 \mathrm{~mm}$ diâmetro, geralmente comprimidas a levemente curvas, paredes estriadas, glabras, negras. Pápus ausente.

Parátipo: BRASIL. PARÁ: Soure, Ilha do Marajó, fazenda Ribanceira, caminho que segue para o Retiro São Cristóvão, 18/XI/1969, fl., fr., E. Oliveira 5103 (IAN).

Distribuição geográfica: devido à ausência de outros registros nos demais herbários da Amazônia brasileira, pode-se inferir que a espécie é endêmica do município de Soure, da Ilha do Marajó, Pará.

Acmella marajoensis é próxima de A. uliginosa por apresentar-se ereta, com hábito herbáceo, capítulos pequenos e corola com 4 lacínios, entretanto, distingue-se desta por possuir capítulos discóides, anteras com tecas castanho-claras, cipselas glabras, levemente curvas e pápus ausente.

O epíteto específico é uma homenagem a Ilha do Marajó, maior ilha flúvio-marítima do mundo, local de coleta da espécie. A nova espécie eleva o número de representantes do gênero Acmella para 31, bem como, para seis o número de espécies ocorrentes na Amazônia brasileira.

\section{AGRADECIMENTOS}

Os autores agradecem ao Museu Paraense Emílio Goeldi e a Universidade Federal Rural da Amazônia pela utilização da infra-estrutura; a CAPES pela concessão de bolsa ao primeiro autor; à curadora do Herbário IAN, Dra Regina Célia Viana Martins da Silva, pela presteza durante as consultas à coleçáo; aos revisores pelas valiosas sugestóes; ao Dr. Tarciso Filgueiras (IBGE), pela versão latina da diagnose e ao ilustrador botânico Carlos Alvarez, pela confecção da prancha em nanquim.

\section{BIBLIOGRAFIA CITADA}

Baker, J.G. 1884. Compositae I. Helianthoideae, p. 19-268. In: Martius, C.F.P.; Eichler, A.G.; Urban, I. (eds.). Flora Brasiliensis. Munchen, Wien, Leipzig. (In latin).

Hickey, J.L. 1973. Classification of the Architecture of Dicotiledoneous leaves. American Journal of Botany, 60 (1): 17-33.

Holmgren, P.K.; Holmgren, N.H.; Barnet, L.C. 1990. Index Herbariorum. 8. Ed. part. I: The Herbaria of the World. New York: New York Botanical Garden. 452 pp.

Jansen, R.K. 1981. Systematics of Spilanthes (Compositae: Heliantheae). Systematic Botany 6: 231-257.

Jansen, R.K. 1985. The systematics of Acmella (AsteraceaeHeliantheae). Systematic Botany Monographs 8: 1-115.

Mondin, C.A.; Magenta, M.; Nakajima, J. 2010. Acmella. In: Check-list of Species to Brazilian Flora. Jardim Botânico do Rio de Janeiro. (http://floradobrasil.jbrj.gov.br/2010/FB103227). (In portuguese).

Moore, A.H. 1906. Revision of the Genus Spilanthes. Contributions from the Gray Herbarium of Harvard University (33): 521-569.

Radford, A.E.; Dickson, W.C.; Massey, J.R.; Bell, C.R. 1974. Vascular Plant Systematic. New York: Harper \& Row. 891 pp.

Rizzini, C.T. 1977. Systematization terminological for the leaf. Rodriguesia. Ano XXIV. 42: 103-125. (In portuguese, with abstract in english).

Silva, G.A.R. 2008. The subtribe Ecliptinae Less. (Heliantheae Asteraceae) for the brazilian Amazonia. Dissertação de Mestrado em Botânica. Museu Paraense Emílio Goeldi/Universidade Federal Rural da Amazônia. 129 pp. (In portuguese, with abstract in english).

Recebido em 11/03/2010

Aceito em 07/09/2010 